\title{
RESEARCH
}

Open Access

\section{Socioeconomic inequalities in the place of death in urban small areas of three Mediterranean cities}

\author{
Andreu Nolasco ${ }^{1}$, Manuel Fernández-Alcántara², Pamela Pereyra-Zamora ${ }^{1 *}$ D , María José Cabañero-Martínez ${ }^{3,4}$,
} José M. Copete ${ }^{1}$, Adriana Oliva-Arocas ${ }^{1}$ and Julio Cabrero-García ${ }^{3}$

\begin{abstract}
Background: Dying at home is the most frequent preference of patients with advanced chronic conditions, their caregivers, and the general population. However, most deaths continue to occur in hospitals. The objective of this study was to analyse the socioeconomic inequalities in the place of death in urban areas of Mediterranean cities during the period 2010-2015, and to assess if such inequalities are related to palliative or non-palliative conditions.

Methods: This is a cross-sectional study of the population aged 15 years or over. The response variable was the place of death (home, hospital, residential care). The explanatory variables were: sex, age, marital status, country of birth, basic cause of death coded according to the International Classification of Diseases, 10th revision, and the deprivation level for each census tract based on a deprivation index calculated using 5 socioeconomic indicators. Multinomial logistic regression models were adjusted in order to analyse the association between the place of death and the explanatory variables.

Results: We analysed a total of 60,748 deaths, 58.5\% occurred in hospitals, 32.4\% at home, and $9.1 \%$ in residential care. Death in hospital was $80 \%$ more frequent than at home while death in a nursing home was more than $70 \%$ lower than at home. All the variables considered were significantly associated with the place of death, except country of birth, which was not significantly associated with death in residential care. In hospital, the deprivation level of the census tract presented a significant association $(p<0.05)$ so that the probability of death in hospital vs. home increased as the deprivation level increased. The deprivation level was also significantly associated with death in residential care, but there was no clear trend, showing a more complex association pattern. No significant interaction for deprivation level with cause of death (palliative, not palliative) was detected.

Conclusions: The probability of dying in hospital, as compared to dying at home, increases as the socioeconomic deprivation of the urban area of residence rises, both for palliative and non-palliative causes. Further qualitative research is required to explore the needs and preferences of low-income families who have a terminally-ill family member and, in particular, their attitudes towards home-based and hospital-based death.
\end{abstract}

Keywords: Mortality, Inequalities, Small-area analysis, Palliative care, Residential facilities, Place of death

\footnotetext{
*Correspondence: pamela.pereyra@ua.es

'Research Unit for the Analysis of Mortality and Health Statistics, Department of Community Nursing, Preventive Medicine, Public Health and History of Science, University of Alicante, Alicante, Spain

Full list of author information is available at the end of the article
}

(c) The Author(s). 2020 Open Access This article is licensed under a Creative Commons Attribution 4.0 International License, which permits use, sharing, adaptation, distribution and reproduction in any medium or format, as long as you give appropriate credit to the original author(s) and the source, provide a link to the Creative Commons licence, and indicate if changes were made. The images or other third party material in this article are included in the article's Creative Commons licence, unless indicated otherwise in a credit line to the material. If material is not included in the article's Creative Commons licence and your intended use is not permitted by statutory regulation or exceeds the permitted use, you will need to obtain permission directly from the copyright holder. To view a copy of this licence, visit http://creativecommons.org/licenses/by/4.0/ The Creative Commons Public Domain Dedication waiver (http://creativecommons.org/publicdomain/zero/1.0/) applies to the data made available in this article, unless otherwise stated in a credit line to the data. 


\section{Background}

Interest in the study of decision-making regarding the place of death has increased in recent decades $[1,2]$. Dying at home is the most frequent preference of patients with advanced chronic diseases [3-6], their caregivers [4], and the general population [4], and so it has become an indicator of the quality of palliative care [7]. However, up until today, most deaths continue to occur in hospitals $[6,8]$.

Place of death predictors are traditionally grouped into three categories: disease-related factors, individual factors, and environmental factors [2]. Research on these predictors through death certificates has usually examined a country's global information, or that of a region, a municipality, or a specific population subgroup in relation to individual factors such as age $[6,7,9,10]$, sex $[6,7,9,10]$, educational level $[7,11]$, marital status $[6,10]$, place of residence in the rural or urban context $[6,7]$ or the patient's own preferences [2]. Similarly, the relationship with disease factors, like the diagnosis of the patient's pathology [6-8, 12-14] and environmental factors such as the availability of family support and home care resources [15-17], as well as other more generally related to or derived from local laws or health policies, has also been examined $[6,18]$.

In addition, recent studies have also explored the relationship between place of death and aggregate indicators of socioeconomic deprivation [11, 19] with the areas of greatest deprivation being those with the highest hospital mortality rates. Furthermore, various studies seem to indicate that social differences have a lesser effect on the place of death when measured at the individual level (for example, educational level) than when measured at the aggregate level (commonly by means of deprivation at the area level) [19]. In this regard, an adequate instrument to measure inequalities is a deprivation index (DI), like those used in the MEDEA and INEQ-CITIES studies on social inequalities and risk of death [20-22], that combine a set of indicators such as the percentages of unemployed, temporary workers, low educational level of different population groups, or manual workers and allow classifying small geographic areas according to their level of socioeconomic deprivation [23].

In Spain, although some retrospective studies have included indicators of deprivation with respect to the place of death, they have only done so for some specific pathologies [24-26]. No studies of the relationship between these indices of deprivation and place of death for general mortality and according to different causes of death have been carried out as far as this team is aware. Knowledge of these aspects, especially in urban settings, where the majority of the population in Europe and Spain concentrates, would allow the adoption of organizational and guidance measures for health services, particularly those related to palliative care and end-of-life care.
Therefore, the objective of this study was to analyse the socioeconomic inequalities in the place of death among the deaths in the large cities of the Valencian Community (Alicante, Castellón, and Valencia) during the period 2010-2015, using levels of deprivation by small areas of the cities, and also to assess if such inequalities are different depending on palliative (oncological, non-oncological) or non-palliative causes of death.

\section{Methods \\ Study design}

This is a cross-sectional study of the resident population in the cities of Alicante, Castellón, and Valencia aged 15 years or over whose death took place between 2010 and 2015. These cities are located on the Mediterranean coast, in the Valencian Community, with an average annual population during the study period of 333,198 inhabitants in Alicante, 177,784 in Castellón, and 794,874 in Valencia.

\section{Data sources and variables}

All deaths of residents in those cities during the study period were included in the analysis. Data obtained from the Valencian Community Mortality Registry, anonymised and included in the Medical Death Certificate Statistical Death Bulletin (Spanish initials: CMD-BED), were used. For each city, deaths were geo-referenced and assigned to their resident census tract (CT) using the address included in the CMD-BED.

The response variable was the place of death. The Spanish registry of deaths includes five possible categories for this variable: home, hospital, residential care, place of work, or other, and the place may be left blank (not recorded). Deaths in the first three places were the focus of this analysis.

The explanatory variables included in the CMD-BED, were: sex (male, female); age (15-64, 65-74, 75-84, 85 and over); marital status (not declared, single, widowed, separated, married); place of birth (Spain, another country) and basic cause of death coded according to the International Classification of Diseases, 10th revision (ICD-10). As this research is based on retrospective anonymized administrative data, the approval of the ethical committee is not necessary for its implementation in Spain.

\section{Causes of death}

Deaths were classified, according to the cause of death, as:

1 Deaths due to 'conditions needing palliative care' (CNPC), according to the classification suggested by Murtagh et al. [27], slightly modified by Gomes et al. [10], which includes the following ICD-10 codes: malignant neoplasm, C00-C97; heart disease: I00-I52 (excluding I12 and I13.1); cerebrovascular 
disease, I60-I69; renal disease, N17, N18, N28, I12, I13,1; liver disease, K70-K77; respiratory disease: J06-J18, J20-J22; J40-J47, J96; neurodegenerative disease: G10, G20, G35, G12,2, G90,3, G23,1; Alzheimer's disease, dementia, and senility: F01, F03, G30, R54, and HIV/AIDS: B20-B24. These causes of death susceptible to palliative care were further subdivided into 'oncological conditions needing palliative care' (OCNPC, including only malignant neoplasm) and 'non-oncological conditions needing palliative care' (NOCNPC, other deaths from CNPC).

2 Deaths from any other condition not needing palliative care (CnotPC).

Thus, the result is the variable 'type of cause' with 3 categories: OCNPC, NOCNPC, CnotPC.

\section{Socioeconomic level}

In each city, a deprivation index (DI) was calculated for each CT from the following indicators: unemployment, manual workers, temporary employees, insufficient instruction in young people (16 to 29 years old), and insufficient instruction in general, all of them in percentage and obtained from the Spanish Population and Housing Census of 2011. These indicators have been used in the coordinated national project MEDEA to construct a deprivation index through a principal components analysis based on census data in the main Spanish cities [23]. The index used in this study was developed within the framework of the MEDEA III project (third edition of the coordinated MEDEA project).

The DI values of each CT, in each city, were classified by percentiles: $10\left(\mathrm{P}_{10}\right), 25\left(\mathrm{P}_{25}\right), 75\left(\mathrm{P}_{75}\right)$, and $90\left(\mathrm{P}_{90}\right)$, according to the methodology described in Oliva-Arocas et al. (2020) [28] that classifies the CT into five levels of deprivation (DL) according to its value: (DL1, DI values below $\mathrm{P}_{10}$; DL2, DI values between $\mathrm{P}_{10}$ and $\mathrm{P}_{25}$; DL3 DI values between $P_{25}$ and $P_{75}$; DL4 DI values between $P_{75}$ and $\mathrm{P}_{90}$ and DL5, values DI higher than $\left.\mathrm{P}_{90}\right)$. This classification was defined, according to the objective of the study, to identify and quantify the most extreme inequality, that between the most socioeconomically favoured areas (DL1) and the most deprived areas (DL5).

\section{Statistical analysis}

Frequencies and percentages were calculated for the following variables: death place (home, hospital, and residential care), cause of death (CNPC, OCNPC, NOCNPC, CnotPC), and deprivation level (DL). To compare the frequencies of death between places of death, the excesses of probability of death ('odds') in hospital and residential care were calculated dividing the percentage of death in each location by the percentage of death at home. The Nelson approximation was used in order to calculate the 95\% confidence intervals (95\% CI) [29].

Multinomial logistic regression models were adjusted in order to analyse the association between the place of death and the DL, with the place of death (home, hospital, or residential care) as the response variable and the DL as the explanatory. Simple and adjusted models taking into account the rest of the sociodemographic variables were estimated. In addition, the existence of different socioeconomic inequalities according to the type of cause was surveyed by including in the model an interaction term between the DL and the type of cause. Finally, in all the models, the reference category was domicile (D), estimating the 'odds ratio'(OR), and its corresponding $95 \% \mathrm{CI}$, as a measure of association. The SPSS statistical program version 25 was used, with a 0.05 level to establish statistical significance.

\section{Results}

From 2010 to 2015, there were 67,521 deaths among the resident population in the cities under study, of which 67,200 ( $99.5 \%$ of the total) occurred in the population aged 15 or over. Of these, $876(1.3 \%)$ could not be assigned to their census tract of residence due to the unavailability of a valid residence address or that it did not belong to the city. Of the 66,324 deaths, 60,748 occurred at home, hospital, or residential care facilities, and therefore they were used in the data analysis. Of these, 49,021 were related to CNPC.

\section{Differences between death in hospital and residential care versus home}

A total of $58.5 \%$ of deaths occurred in hospitals, $32.4 \%$ at home, and $9.1 \%$ in residential care (see Table 1).

The percentage of death in hospitals ranged from a minimum of $47.3 \%$ in people aged 85 and over to a maximum of $81.2 \%$ in people aged 15 to 44 years. At home, it went from $16.5 \%$ in people aged $15-44$ to $39.8 \%$ in people residing in the DL1 areas (the areas with better socioeconomic status). For residential care, the death rates oscillated between $2.3 \%$ in subjects aged 15 to 44 years and $14.4 \%$ in those over 85 years of age. Death in hospital was $80 \%$ more frequent than at home (Odds for hospital vs. home $=\mathrm{O}_{\mathrm{H} / \mathrm{D}}=1.806$ ), while death in the nursing home was more than $70 \%$ lower than at home (Odds for residential care vs. home $=\mathrm{O}_{\mathrm{R} / \mathrm{D}}=0.281$ ).

When comparing hospital with domicile (home), the $\mathrm{O}_{\mathrm{H} / \mathrm{D}}$ were significantly greater than $1(p<0.05)$ for any category of the explanatory variables, with the highest excesses of death in men, residents of the city of Alicante, aged between 15 and 44 years old, divorced, and born in another country. Death in hospital was significantly more frequent for CnotPC, followed by OCNPC and finally NOCNPC. Regarding the socioeconomic level 
Table 1 Percentages, frequencies ( $n$ ) and Odds of death in each location compared to death at home, according to the categories of the variables studied. Alicante, Castellón and Valencia. 2010-2015

\begin{tabular}{|c|c|c|c|c|c|c|c|c|c|c|}
\hline \multirow{4}{*}{$\begin{array}{l}\text { VARIABLE } \\
\\
\text { TOTAL }\end{array}$} & \multicolumn{3}{|c|}{$\begin{array}{l}\text { Percentages of death according to place of } \\
\text { death }^{\mathrm{a}}\end{array}$} & \multirow{4}{*}{$\begin{array}{l}n \\
\\
60,748\end{array}$} & \multicolumn{6}{|c|}{$\begin{array}{l}\text { Odds of death in each location compared to death at } \\
\text { home }^{b}\end{array}$} \\
\hline & \multirow{3}{*}{$\begin{array}{l}\text { Home } \\
32.4\end{array}$} & \multirow{3}{*}{$\begin{array}{l}\text { Hospital } \\
58.5\end{array}$} & \multirow{3}{*}{$\begin{array}{l}\text { Resid. care } \\
9.1\end{array}$} & & \multicolumn{3}{|c|}{ Hospital } & \multicolumn{3}{|c|}{ Residential care } \\
\hline & & & & & \multirow{2}{*}{$\begin{array}{l}\text { Odds } \\
1.806\end{array}$} & \multicolumn{2}{|c|}{$95 \% \mathrm{IC}$} & \multirow{2}{*}{$\begin{array}{l}\text { Odds } \\
0.281\end{array}$} & \multicolumn{2}{|l|}{$95 \% \mathrm{IC}$} \\
\hline & & & & & & 1.774 & 1.837 & & 0.273 & 0.289 \\
\hline \multicolumn{11}{|l|}{ CITY } \\
\hline Alicante & 31.5 & 60.7 & 7.9 & 14,316 & 1.927 & 1.859 & 1.998 & 0.251 & 0.235 & 0.268 \\
\hline Castellón & 32.3 & 57.6 & 10.1 & 7,286 & 1.783 & 1.696 & 1.876 & 0.313 & 0.288 & 0.340 \\
\hline Valencia & 32.8 & 57.9 & 9.4 & 39,146 & 1.765 & 1.727 & 1.804 & 0.287 & 0.276 & 0.297 \\
\hline \multicolumn{11}{|l|}{ SEX } \\
\hline Men & 30.5 & 63.8 & 5.7 & 29,112 & 2.092 & 2.040 & 2.145 & 0.187 & 0.177 & 0.197 \\
\hline Women & 34.2 & 53.6 & 12.2 & 31,636 & 1.567 & 1.530 & 1.606 & 0.357 & 0.344 & 0.370 \\
\hline \multicolumn{11}{|l|}{ AGE } \\
\hline $15-44$ & 16.5 & 81.2 & 2.3 & 919 & 4.921 & 4.134 & 5.859 & 0.139 & 0.088 & 0.220 \\
\hline $45-64$ & 23.4 & 75.0 & 1.6 & 6,876 & 3.205 & 3.031 & 3.390 & 0.068 & 0.056 & 0.083 \\
\hline $65-84$ & 29.7 & 63.9 & 6.3 & 27,498 & 2.152 & 2.096 & 2.209 & 0.212 & 0.201 & 0.223 \\
\hline$\geq 85$ & 38.3 & 47.3 & 14.4 & 25,455 & 1.235 & 1.202 & 1.268 & 0.376 & 0.362 & 0.391 \\
\hline \multicolumn{11}{|l|}{ MARITAL STATUS } \\
\hline Not included & 26.3 & 62.4 & 11.3 & 1,997 & 2.373 & 2.143 & 2.627 & 0.430 & 0.368 & 0.502 \\
\hline Single & 27.1 & 59.2 & 13.7 & 5,694 & 2.185 & 2.057 & 2.320 & 0.506 & 0.464 & 0.551 \\
\hline Widowed & 35.0 & 51.5 & 13.5 & 25,652 & 1.471 & 1.433 & 1.511 & 0.386 & 0.371 & 0.401 \\
\hline Divorced & 21.3 & 72.3 & 6.4 & 2,347 & 3.394 & 3.072 & 3.750 & 0.300 & 0.250 & 0.361 \\
\hline Married & 32.5 & 63.9 & 3.6 & 25,058 & 1.966 & 1.914 & 2.019 & 0.111 & 0.103 & 0.119 \\
\hline \multicolumn{11}{|l|}{ COUNTRY OF BIRTH } \\
\hline Spain & 32.5 & 58.3 & 9.2 & 59,176 & 1.794 & 1.762 & 1.826 & 0.283 & 0.275 & 0.292 \\
\hline Other & 27.4 & 66.2 & 6.4 & 1,572 & 2.416 & 2.159 & 2.703 & 0.234 & 0.188 & 0.290 \\
\hline \multicolumn{11}{|l|}{ DEPRIVATION LEVEL ${ }^{c}$} \\
\hline DL1 & 39.8 & 52.7 & 7.5 & 4,907 & 1.324 & 1.249 & 1.404 & 0.188 & 0.169 & 0.211 \\
\hline DL2 & 34.0 & 54.2 & 11.8 & 9,957 & 1.594 & 1.527 & 1.664 & 0.347 & 0.325 & 0.371 \\
\hline DL3 & 31.7 & 59.0 & 9.2 & 30,997 & 1.861 & 1.816 & 1.907 & 0.290 & 0.278 & 0.303 \\
\hline DL4 & 31.0 & 61.4 & 7.6 & 8,971 & 1.981 & 1.892 & 2.073 & 0.245 & 0.225 & 0.267 \\
\hline DL5 & 29.4 & 63.2 & 7.3 & 5,916 & 2.150 & 2.031 & 2.275 & 0.248 & 0.223 & 0.276 \\
\hline \multicolumn{11}{|l|}{ CAUSE OF DEATH } \\
\hline No palliative & 22.0 & 69.8 & 8.1 & 11,727 & 3.173 & 3.035 & 3.316 & 0.368 & 0.342 & 0.397 \\
\hline Palliative oncologic & 31.6 & 65.5 & 2.9 & 18,044 & 2.073 & 2.008 & 2.139 & 0.092 & 0.084 & 0.100 \\
\hline Palliative no oncologic & 36.8 & 50.1 & 13.1 & 30,977 & 1.361 & 1.329 & 1.395 & 0.356 & 0.343 & 0.369 \\
\hline
\end{tabular}

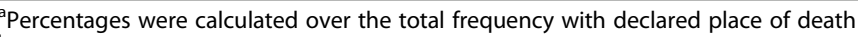

bodds (location/home) $=$ Percentage of death in this location/Percentage of death at home

${ }^{C} D L$ : Deprivation level of the census track of residence based on the deprivation index (DI). DL1: $D I<P_{10} ; D L 2: P_{10} \leq D I<P_{25} ; D L 3: P_{25} \leq D I<P_{75} ; D L 4: P_{75} \leq D I<P_{90}$; $\mathrm{DL} 5: \mathrm{DI} \geq \mathrm{P}_{90} ; \mathrm{P}_{\mathrm{q}}=$ Percentile $\mathrm{q}$

of the area of residence, a clear trend was observed in excesses of death in hospital vs. home, from the better off level, DL1 $\left(\mathrm{O}_{\mathrm{H} / \mathrm{D}}=1.324\right)$ to the worst off one, DL5 $\left(\mathrm{O}_{\mathrm{H} / \mathrm{D}}=2.150\right)$.

For residential care, the $\mathrm{O}_{\mathrm{R} / \mathrm{D}}$ was always significantly $(p<0.05)$ less than 1 , with lower mortality in men, residents in Alicante, aged between 45 and 64 years, married, and born in another country. Compared to domicile, death in residential care was lower for OCNPC, with NOCNPC and CnotPC presenting similar deficits. The socioeconomic level of the area of residence did not present a clear trend, with low values both in favoured levels such as DL1 and high deprivation levels such as DL5. 
Regarding overall mortality, Fig. 1 shows both a slight decrease of deaths in hospital and a slight increase of deaths in residential care homes from the beginning to the end of the period with statistically significant differences $(p<0.001)$ for these two settings. As well, there is a slight increase in residential care deaths for CnotPC. Deaths at home remained stable over time.

\section{Specific conditions needing palliative care}

Table 2 shows the percentages and Odds of death by location for deaths from specific CNPC and the rest of the causes.

Comparing death in hospital vs. home, heart disease was the only cause with $\mathrm{O}_{\mathrm{H} / \mathrm{D}}<1$, although not significant. The rest presented $\mathrm{O}_{\mathrm{H} / \mathrm{D}}$ significantly higher than 1 $(p<0.05)$. Among the CNPC, death from HIV/AIDS had the highest odds of death in hospital vs. home, followed by liver disease. Death from malignant neoplasm was located in an intermediate $\mathrm{O}_{\mathrm{H} / \mathrm{D}}$. The rest of the CnotPC had a large excess of death in hospital.

Regarding death in residential care, all causes presented $\mathrm{O}_{\mathrm{R} / \mathrm{D}}$ significantly lower than $1(p<0.05)$. The low $\mathrm{O}_{\mathrm{R} / \mathrm{D}}$ value for malignant neoplasm stood out, followed by liver disease. The CnotPC reached an intermediate mortality deficit in residential care.

\section{Association between the place of death and level of deprivation}

Table 3 shows the crude and adjusted OR that estimate the association between the place of death and the explanatory variables. All the variables considered were significantly associated with the place of death, in the simple and multivariate analysis models, except country of birth, which was not significantly associated with death in residential care.

The multivariate model with all variables had indices pseudo-R2 Cox and Snell $=0.1034$ and Nagelkerke = 0.1240 . The adjusted ORs showed that the level of deprivation of the CT presented a significant association $(p<0.05)$ and increased from the lowest DL to the highest one. That is, the probability of death in hospital vs. home increased as the deprivation level raised. In addition, the highest probability of death in hospital vs. home was associated with residing in the city of Alicante, male sex, younger age, marital status different from married, and place of birth outside of Spain. The probability of death in hospital vs. home was higher for CnotPC, followed by OCNPC, vis-à-vis the NOCNPC.

The level of CT deprivation was also significantly associated with death in residential care, but with lower ORs than in the case of death in hospital and with a diffuse pattern, since both highly deprived and less deprived CTs presented excesses of the probability of death over the reference level (DL1). Regarding the other variables, the highest probability of death in residential care vs. home occurred in Castellón, in relation to old women, of any marital status other than married, and without significant association with the country of birth. Only OCNPC presented a significant deficit in deaths.

The estimated ORs of association between DL and place of death represent a measure of the level of inequality in the probability of death according to the level of deprivation of the area of residence. To check if these inequalities could be different depending on the cause of death (OCNPC, NOCNPC, CnotPC), an interaction term between DL and cause of death was added to the previous multivariate model. The resulting model presented indices pseudo-R2 Cox and Snell $=0.1037$ and Nagelkerke = 0.1244, with little variation with the interaction-less model. Furthermore, the interaction term was not significant $(p=0.221)$, meaning that the estimated inequalities are not different according to these cause groupings.

The effect of sex on the relationship between DL and place of death was also checked by adding an interaction term between DL and sex to the main effects model. Nevertheless, the interaction term was not significant $(p=0.322)$ and presented indices pseudo- 22 Cox and Snell $=0.1036$ and Nagelkerke $=0.1242$, with little variation with the interaction-less model. This suggests that sex does not substantially alter the deprivation effect.

To delve into the causes that presented the highest association between death in hospital and the level of deprivation, multinomial logistic regression models were adjusted for each of the CNPC and also the CnotPC. Table 4 presents the ORs between death in hospital vs. home and level of deprivation, adjusted by the rest of the explanatory variables (city, sex, age, marital status, and country of birth). Mortality due to respiratory disease, Alzheimer's disease, dementia and senility, and mortality from CnotPC were noticeable for their significant and high association with the DL as compared with mortality by the rest of the causes of death. This effect has contributed to a greater extent to the global association. Mortality from malignant neoplasm and heart disease also presented a significant but lower association with DL than that of the group of all deaths. Regarding the rest of the causes, no significant association with DL was detected.

\section{Discussion}

The objective of this study was to analyse the socioeconomic inequalities in the place of death in the large cities of the Valencian Community (Alicante, Castellón, and Valencia) during the period 2010-2015, using levels of socioeconomic deprivation by small areas of the cities. A part of our aims was to assess if such inequalities were different depending on whether the deaths were due to conditions needing palliative care (oncological, nononcological) or conditions not needing palliative care. 

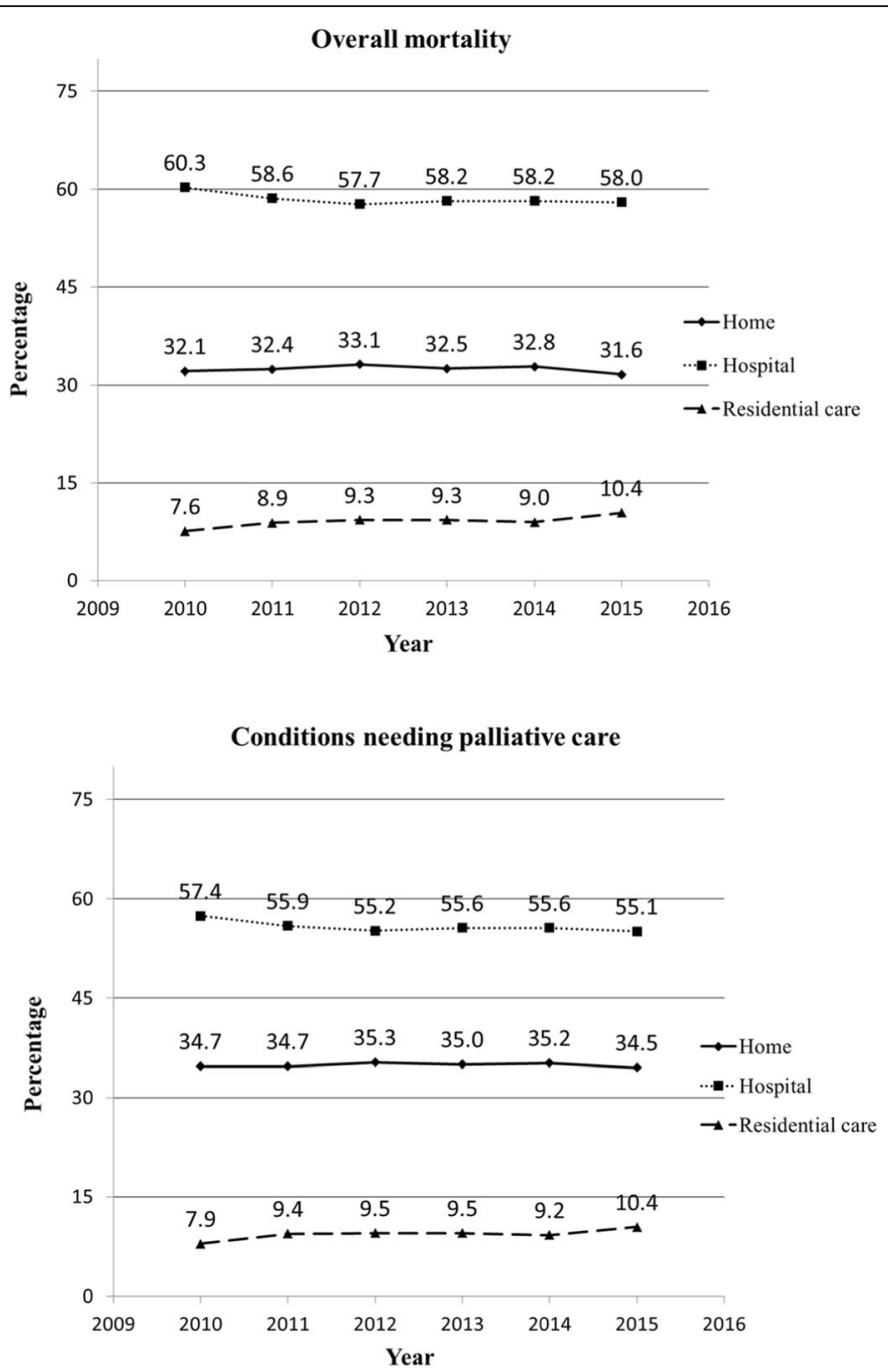

Conditions not needing palliative care

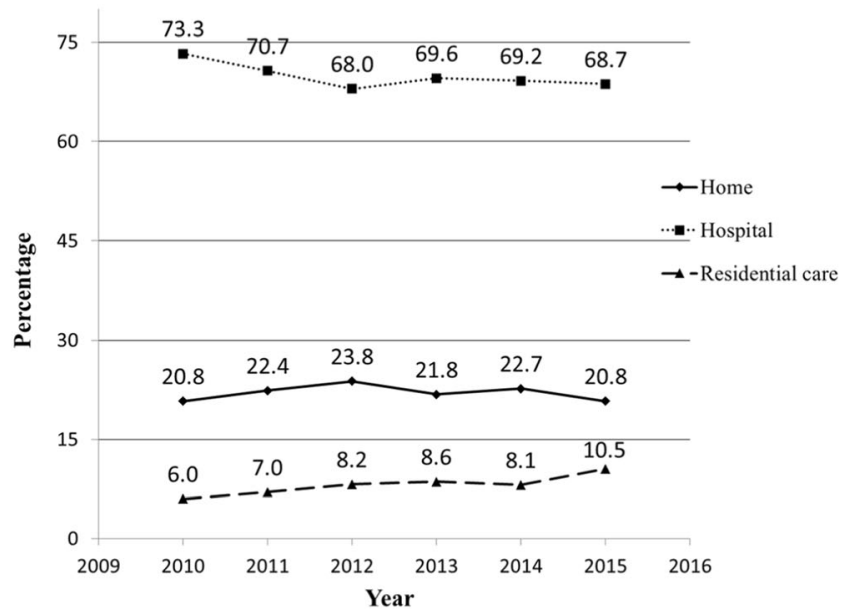

Fig. 1 Percentage of death by place and year. Alicante, Castellón and Valencia. 2010-15 
Table 2 Percentages, frequencies and odds of death in each location compared to death at home according specific palliative/nonpalliative causes. Alicante, Castellón and Valencia. 2010-2015

\begin{tabular}{|c|c|c|c|c|c|c|c|c|c|c|}
\hline \multirow[t]{3}{*}{ CAUSE OF DEATH } & \multicolumn{3}{|c|}{$\begin{array}{l}\text { Percentages of death according to } \\
\text { place of death }\end{array}$} & \multirow[t]{3}{*}{$\begin{array}{l}\text { Frequency } \\
\text { of death }\end{array}$} & \multicolumn{6}{|c|}{$\begin{array}{l}\text { Odds of death in each location compared to death } \\
\text { at home }{ }^{\text {b }}\end{array}$} \\
\hline & \multirow[t]{2}{*}{ Home } & \multirow[t]{2}{*}{ Hospital } & \multirow[t]{2}{*}{ Resid. care } & & \multicolumn{3}{|c|}{ Hospital } & \multicolumn{3}{|c|}{ Residential care } \\
\hline & & & & & Odds & $95 \% I C$ & & Odds & $95 \% \mathrm{IC}$ & \\
\hline TOTAL & 32.4 & 58.5 & 9.1 & 60,748 & 1.806 & 1.774 & 1.837 & 0.281 & 0.273 & 0.289 \\
\hline Malignant neoplasm & 31.6 & 65.5 & 2.9 & 18,044 & 2.073 & 2.008 & 2.139 & 0.092 & 0.084 & 0.100 \\
\hline Heart disease & 44.0 & 43.9 & 12.1 & 13,232 & 0.998 & 0.962 & 1.035 & 0.275 & 0.260 & 0.291 \\
\hline Cerebrovascular disease & 28.1 & 62.8 & 9.0 & 4145 & 2.235 & 2.086 & 2.395 & 0.320 & 0.285 & 0.360 \\
\hline Renal disease & 33.4 & 55.2 & 11.4 & 1,202 & 1.653 & 1.460 & 1.871 & 0.341 & 0.281 & 0.414 \\
\hline Liver disease & 21.4 & 75.0 & 3.6 & 917 & 3.505 & 2.990 & 4.107 & 0.168 & 0.116 & 0.243 \\
\hline Respiratory disease & 25.8 & 65.7 & 8.5 & 4,602 & 2.547 & 2.381 & 2.723 & 0.329 & 0.294 & 0.369 \\
\hline Neurodegenerative disease & 41.9 & 45.1 & 12.9 & 904 & 1.076 & 0.936 & 1.238 & 0.308 & 0.250 & 0.379 \\
\hline Alzheimer's. dementia and senility & 39.0 & 37.1 & 23.9 & 5,755 & 0.951 & 0.897 & 1.009 & 0.613 & 0.573 & 0.655 \\
\hline HIV/AIDS & 8.6 & 85.5 & 5.9 & 220 & 9.942 & 6.202 & 15.936 & 0.686 & 0.339 & 1.389 \\
\hline Other non-palliative causes & 22.0 & 69.8 & 8.1 & 11,727 & 3.173 & 3.035 & 3.316 & 0.368 & 0.342 & 0.397 \\
\hline
\end{tabular}

a Percentages were calculated over the total frequency with declared place of death

${ }^{\mathrm{b}}$ Odds (location/home) $=$ Percentage of death in this location/Percentage of death at home

The results have highlighted the existence of socioeconomic inequalities in the sense that greater deprivation would clearly increase the probability of death in hospital vs. home. This effect is not so evident in the case of death in a nursing home. There was no evidence to affirm that the estimated inequalities are different according to the different cause of death groupings. As in previous research [13], other sociodemographic variables such as country of birth, sex, age, marital status, or cause of death have also been associated with place of death.

Importantly, the Survey of Care for Patients with Terminal Illness shows that in 2009 the Spanish population (18+ years) preferred to be cared for at home (45.0\%), followed by care in a specialized center (31.9\%) and only $17.8 \%$ would choose a hospital in the case of irreversible disease in terminal phase [30]. This shows the high percentage of the population that prefers to end their days of life at home.

Regarding the excesses of deaths in hospital vs. home, significantly higher values were observed in the most deprived CT, especially in respiratory disease, Alzheimer's disease, malignant neoplasm, heart disease, and other non-palliative causes. In all cases, an association was observed between living in areas with greater deprivation and probability of dying in hospital, as indicated by previous studies $[11,19,31,32]$. This is an important result since death at home is usually considered an indicator of the quality of palliative care services $[3,10]$. The higher number of deaths in hospital may be related to the difficulty that people living in CT with higher deprivation have to access health resources, which might not reach these patients adequately [11]. Likewise, it is possible that, in line with what other authors suggest, people who live in a place with greater deprivation prefer to die in hospital as compared to home or residential care home [33, 34], as well as other contextual factors that might be at work, such as the difficult economic or labour situation associated with the places of greatest deprivation [19].

Another possible explanation for these results has to do with the care burden and social support to the caregivers. A lower socioeconomic level is associated with a greater burden of care, and a greater difficulty in receiving formal support. The burden of care has been associated, in many cases, with the need for help in daily life tasks, rather than with the specific symptoms presented by the patient [35]. This burden of care can make caregivers prefer to have their family members dying in hospital, where there are more resources and will receive more support to cope with the end of life.

In this regard, a recent qualitative study explored the relationships between social disparities and the burden of care in cancer patients and showed how the social determinants of health such as low income, low education, precarious housing conditions, rurality (associated with difficulty in the access to palliative care) or lack of social support could exacerbate the caregiver's overload [36]. Likewise, social support is an important variable that can mediate and positively regulate the perceived care burden $[37,38]$. Neergaard et al. identified in their review a series of variables related to social support such as living with other family members, having family support, being married, availability of space at home, the region of residence, as well as the caregiver's sociodemographic variables (age, sex, and relationship with the patient) [19]. 
Table 3 Association $^{\text {a }}$ between place of death and studied variables. Odds Ratios (OR) for each place of death vs. reference category (home). Alicante, Castellón and Valencia. 2010-2015

\begin{tabular}{|c|c|c|c|c|c|c|c|c|c|c|c|c|}
\hline \multirow{2}{*}{$\begin{array}{l}\text { VARIABLE } \\
\text { CITY }\end{array}$} & \multicolumn{6}{|l|}{ Hospital } & \multicolumn{6}{|c|}{ Residential care } \\
\hline & Crude OR & \multicolumn{2}{|c|}{$95 \% \mathrm{Cl}^{\mathrm{b}}$} & Adjusted OR & \multicolumn{2}{|c|}{$95 \% \mathrm{Cl}^{\mathrm{b}}$} & Crude OR & \multicolumn{2}{|c|}{$95 \% \mathrm{Cl}^{\mathrm{b}}$} & Adjusted OR & \multicolumn{2}{|c|}{$95 \% \mathrm{Cl}^{\mathrm{b}}$} \\
\hline Alicante & 1.09 & 1.05 & 1.14 & 1.13 & 1.08 & 1.18 & 0.87 & 0.81 & 0.94 & 0.89 & 0.83 & 0.97 \\
\hline Castellón & 1.01 & 0.95 & 1.07 & 1.05 & 0.99 & 1.11 & 1.09 & 0.99 & 1.19 & 1.12 & 1.02 & 1.23 \\
\hline Valencia & 1.00 & & & 1.00 & & & 1.00 & & & 1.00 & & \\
\hline \multicolumn{13}{|l|}{ SEX } \\
\hline Men & 1.33 & 1.29 & 1.38 & 1.20 & 1.15 & 1.25 & 0.53 & 0.49 & 0.56 & 0.89 & 0.83 & 0.96 \\
\hline Women & 1.00 & & & 1.00 & & & 1.00 & & & 1.00 & & \\
\hline \multicolumn{13}{|l|}{ AGE } \\
\hline $15-44$ & 3.97 & 3.33 & 4.74 & 3.49 & 2.91 & 4.19 & 0.37 & 0.23 & 0.58 & 0.43 & 0.27 & 0.69 \\
\hline $45-64$ & 2.59 & 2.44 & 2.76 & 2.41 & 2.25 & 2.59 & 0.18 & 0.15 & 0.22 & 0.33 & 0.27 & 0.41 \\
\hline $65-84$ & 1.74 & 1.68 & 1.81 & 1.69 & 1.62 & 1.76 & 0.57 & 0.53 & 0.61 & 0.88 & 0.82 & 0.94 \\
\hline$\geq 85$ & 1.00 & & & 1.00 & & & 1.00 & & & 1.00 & & \\
\hline \multicolumn{13}{|l|}{ MARITAL STATUS } \\
\hline Not included & 1.21 & 1.09 & 1.34 & 1.36 & 1.22 & 1.51 & 3.86 & 3.25 & 4.58 & 3.37 & 2.83 & 4.01 \\
\hline Single & 1.11 & 1.04 & 1.19 & 1.14 & 1.06 & 1.22 & 4.56 & 4.08 & 5.09 & 4.03 & 3.59 & 4.53 \\
\hline Widowed & 0.75 & 0.72 & 0.78 & 1.06 & 1.01 & 1.11 & 3.47 & 3.21 & 3.76 & 2.49 & 2.27 & 2.72 \\
\hline Divorced & 1.72 & 1.56 & 1.91 & 1.43 & 1.28 & 1.59 & 2.70 & 2.22 & 3.28 & 3.62 & 2.96 & 4.43 \\
\hline Married & 1.00 & & & 1.00 & & & 1.00 & & & 1.00 & & \\
\hline \multicolumn{13}{|l|}{ COUNTRY OF BIRTH } \\
\hline Other country & 1.35 & 1.20 & 1.51 & 1.16 & 1.03 & 1.31 & 0.82 & 0.66 & 1.03 & 0.94 & 0.75 & 1.18 \\
\hline Spain & 1.00 & & & 1.00 & & & 1.00 & & & 1.00 & & \\
\hline \multicolumn{13}{|l|}{ DEPRIVATION LEVEL ${ }^{c}$} \\
\hline $\mathrm{DL} 5$ & 1.50 & 1.38 & 1.62 & 1.39 & 1.28 & 1.51 & 1.07 & 0.93 & 1.23 & 1.16 & 1.01 & 1.34 \\
\hline DL4 & 1.42 & 1.32 & 1.53 & 1.36 & 1.27 & 1.47 & 1.05 & 0.92 & 1.19 & 1.10 & 0.97 & 1.25 \\
\hline DL3 & 1.32 & 1.24 & 1.41 & 1.27 & 1.19 & 1.35 & 1.09 & 0.98 & 1.21 & 1.17 & 1.05 & 1.30 \\
\hline DL2 & 1.12 & 1.05 & 1.21 & 1.09 & 1.01 & 1.17 & 1.32 & 1.18 & 1.49 & 1.35 & 1.20 & 1.52 \\
\hline DL1 & 1.00 & & & 1.00 & & & 1.00 & & & 1.00 & & \\
\hline \multicolumn{13}{|l|}{ CAUSE OF DEATH } \\
\hline Non-palliative & 2.33 & 2.22 & 2.45 & 2.30 & 2.18 & 2.42 & 1.04 & 0.96 & 1.13 & 1.03 & 0.95 & 1.12 \\
\hline Palliative oncologic & 1.53 & 1.47 & 1.59 & 1.17 & 1.12 & 1.22 & 0.26 & 0.24 & 0.29 & 0.35 & 0.32 & 0.39 \\
\hline Palliative non-oncologic & 1.00 & & & 1.00 & & & 1.00 & & & 1.00 & & \\
\hline
\end{tabular}

${ }^{a}$ Estimation using multinomial regression model with main effects simple and adjusting for all the variables

${ }^{b} 95 \mathrm{Cl}$ : $95 \%$ confidence interval for the OR

${ }^{C} D L$ : Deprivation level of the census track of residence based on the deprivation index (DI). DL1: $D I<P_{10} ; D L 2: P_{10} \leq D I<P_{25} ; D L 3: P_{25} \leq D I<P_{75} ; D L 4: P_{75} \leq D I<P_{90}$; DL5: $\mathrm{DI} \geq \mathrm{P}_{90} ; \mathrm{P}_{\mathrm{q}}=$ Percentile $\mathrm{q}$

Regarding the diagnoses most associated with the different levels of deprivation, a very heterogeneous profile was found. This includes the three trajectories associated with the end-of-life process: advanced cancer (malignant neoplasm), advanced organ disease (heart and respiratory disease), and advanced dementia (Alzheimer's dementia and senility) [39]. In addition to these CNPC, diagnoses for CnotPC were also significant, and deprivation seems to have an important role. This great variability in the diagnoses found is consistent with studies that indicate that the burden of care is similar among those diagnosed with an oncological process or in cases of diseases not related to cancer [35, 40].

Results regarding the risk of death in residential care home vs. home showed a more complex association pattern, with both high and low deprivation CTs showing an excess probability of death in residential care vs. home. An increase in the number of deaths in residential care facilities can be observed, related to the ongoing aging of the population, as well as an increase in 


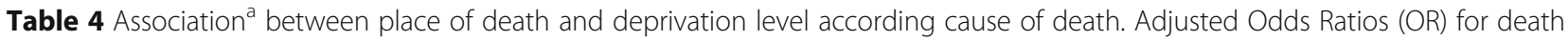
in Hospital vs. reference category (home). Alicante, Castellón and Valencia. 2010-2015

\begin{tabular}{|c|c|c|c|c|c|c|c|c|c|c|c|c|c|c|c|}
\hline \multirow[t]{3}{*}{ VARIABLE } & \multicolumn{15}{|c|}{ Death in Hospital vs. Home } \\
\hline & \multicolumn{3}{|c|}{ Malignant neoplasm } & \multicolumn{3}{|c|}{ Heart disease } & \multicolumn{3}{|c|}{ Cerebrovascular disease } & \multicolumn{3}{|c|}{ Renal disease } & \multicolumn{3}{|c|}{ Liver disease } \\
\hline & OR & \multicolumn{2}{|c|}{$95 \% \mathrm{Cl}^{\mathrm{b}}$} & OR & \multicolumn{2}{|c|}{$95 \% \mathrm{Cl}^{\mathrm{b}}$} & OR & \multicolumn{2}{|c|}{$95 \% \mathrm{Cl}^{\mathrm{b}}$} & OR & \multicolumn{2}{|c|}{$95 \% \mathrm{Cl}^{\mathrm{b}}$} & OR & \multicolumn{2}{|c|}{$95 \% \mathrm{Cl}^{\mathrm{b}}$} \\
\hline \multicolumn{16}{|c|}{ DEPRIVATION LEVEL ${ }^{c}$} \\
\hline DL5 & 1.34 & 1.15 & 1.55 & 1.27 & 1.07 & 1.50 & 1.11 & 0.80 & 1.55 & 1.19 & 0.62 & 2.27 & 1.38 & 0.58 & 3.28 \\
\hline DL4 & 1.26 & 1.10 & 1.44 & 1.20 & 1.03 & 1.40 & 1.46 & 1.09 & 1.96 & 0.88 & 0.51 & 1.50 & 0.97 & 0.45 & 2.08 \\
\hline DL3 & 1.29 & 1.15 & 1.45 & 1.07 & 0.94 & 1.21 & 1.24 & 0.97 & 1.58 & 0.92 & 0.58 & 1.49 & 0.93 & 0.46 & 1.89 \\
\hline DL2 & 1.06 & 0.93 & 1.20 & 1.00 & 0.86 & 1.16 & 1.01 & 0.76 & 1.33 & 0.95 & 0.56 & 1.61 & 1.15 & 0.51 & 2.59 \\
\hline \multirow[t]{3}{*}{ DL1 } & \multicolumn{3}{|l|}{1.00} & \multicolumn{3}{|l|}{1.00} & \multicolumn{3}{|l|}{1.00} & \multicolumn{3}{|l|}{1.00} & \multicolumn{3}{|l|}{1.00} \\
\hline & \multicolumn{3}{|c|}{ Respiratory disease } & \multicolumn{3}{|c|}{ Neurodegenerative disease } & \multicolumn{3}{|c|}{$\begin{array}{l}\text { Alzheimer's. dementia } \\
\text { and senility }\end{array}$} & \multicolumn{3}{|c|}{ HIV/AIDS } & \multicolumn{3}{|c|}{$\begin{array}{l}\text { Other non-palliative } \\
\text { causes }\end{array}$} \\
\hline & OR & \multicolumn{2}{|c|}{$95 \% \mathrm{Cl}^{\mathrm{b}}$} & OR & \multicolumn{2}{|c|}{$95 \% \mathrm{Cl}^{\mathrm{b}}$} & OR & \multicolumn{2}{|c|}{$95 \% \mathrm{Cl}^{\mathrm{b}}$} & OR & \multicolumn{2}{|c|}{$95 \% \mathrm{Cl}^{\mathrm{b}}$} & OR & \multicolumn{2}{|c|}{$95 \% \mathrm{Cl}^{\mathrm{b}}$} \\
\hline \multicolumn{16}{|c|}{ DEPRIVATION LEVEL ${ }^{c}$} \\
\hline DL5 & 2.01 & 1.46 & 2.75 & 1.11 & 0.57 & 2.15 & 1.64 & 1.24 & 2.16 & 1.93 & 0.28 & 13.50 & 1.55 & 1.26 & 1.90 \\
\hline DL4 & 1.52 & 1.16 & 2.00 & 1.66 & 0.92 & 2.97 & 1.70 & 1.33 & 2.18 & 2.30 & 0.31 & 17.34 & 1.65 & 1.37 & 1.99 \\
\hline DL3 & 1.54 & 1.22 & 1.95 & 1.28 & 0.81 & 2.04 & 1.41 & 1.14 & 1.74 & 4.97 & 0.69 & 35.92 & 1.46 & 1.25 & 1.71 \\
\hline DL2 & 1.46 & 1.11 & 1.92 & 0.91 & 0.54 & 1.55 & 1.15 & 0.90 & 1.46 & 3.38 & 0.33 & 35.04 & 0.20 & 1.00 & 1.43 \\
\hline DL1 & 1.00 & & & 1.00 & & & 1.00 & & & 1.00 & & & 1.00 & & \\
\hline
\end{tabular}

${ }^{a}$ Estimation using multinomial regression model with main effects, adjusting for the rest of the explanatory variables (city, sex, age, marital status and country of birth) ${ }^{b} 95 \mathrm{Cl}$ : $95 \%$ confidence interval for the OR

${ }^{c} D L$ : Deprivation level of the census track of residence based on the deprivation index (DI). DL1: $D I<P_{10} ; D_{2}: P_{10} \leq D I<P_{25} ; D L 3: P_{25} \leq D I<P_{75} ; D L 4: P_{75} \leq D I<P_{90}$; DL5: $\mathrm{DI} \geq \mathrm{P}_{90} ; \mathrm{P}_{\mathrm{q}}=$ Percentile $\mathrm{q}$

pathologies such as dementia, which can mean that, regardless of the level of deprivation, many people end up dying in residential care homes. Also, the situation of nursing homes in Spain includes both public and private institutions, and so, regardless of the level of deprivation of a person's CT, it is possible to move to them. In this regard, various studies in countries such as the United States have associated low socioeconomic status with access to poorer quality nursing homes [41, 42].

It is important to highlight that the progressive breakdown of the Spanish health system, in particular primary care and public health, due to the long period of austerity and privatizations (particularly in some regions) [43, 44], plus the overload of care resulting from budget cuts has had a serious impact on the quality of primary care [45]. The consequences of this deterioration have differentially affected the most deprived populations. This may explain why the hospital is the main place of death for many people living in more deprived places.

This work presents a series of limitations among which are those related to the use of data from the CMD-BED, since there may have been undetected errors in the diagnosis or during encoding and transcription. The CMD-BED was not modified during the study period. On the other hand, the CMD-BED in Spain includes a limited number of variables, so it was not possible to consider some of them individually, i.e. the employment situation or the type of work. Instead, the deprivation level variable included information on such variables, considered at the contextual level of the area of residence, and thus, the excess probability of death in one or other locations according to the level of deprivation could reflect both the effect of the individual socioeconomic level as much as the contextual effect of the area of residence.

Another limitation comes from not having georeferenced all deaths. Nevertheless, only a very small percentage (1.3\%), lower than usual in this type of study, was not included. These losses should have had little effect on the results obtained.

It should be borne in mind that the classification in DL would not be the only possible one either. Nevertheless, it responds to the objective of preferentially evaluating the inequality existing between the population groups of greater and lesser deprivation, with consistent results across the different categories used.

Finally, this work did not include preferences about the place of death. Further research is needed to 
investigate the effect that deprivation may have on the congruence or incongruence between the place where a person wants to die and where death finally occurs.

\section{Conclusions}

The results of this study indicate that the probability of dying in hospital as compared to dying at home, increases as the socioeconomic deprivation of the urban area of residence rises, and this generally happens either for any type of palliative death (oncological and nononcological) or non-palliative. However, when comparing death in residential care vs. home it can be seen that the effect of the level of socioeconomic deprivation is very limited since only the areas of least socio-economic deprivation (the first level) are slightly associated with a lower probability of death in residential care. While socioeconomic differences in access to formal and informal care may explain the greater probability of death in hospital for people living in areas of greater deprivation, the way these factors influence death in residential care vs. home is largely unknown. Further qualitative research is required to explore the needs and preferences of lowincome families who have a terminally-ill family member and, in particular, their attitudes towards home-based and hospital-based death.

\section{Abbreviations}

CMD-BED: Medical Death Certificate - Statistical Death Bulletin; ICD10: International Classification of Diseases 10th revision; CT: Census tract; CNPC: Conditions needing palliative care; OCNPC: Oncological conditions needing palliative care; NOCNPC: Non-oncological conditions needing palliative care; CnotPC: Condition not needing palliative care; DI: Deprivation index; DL: Levels of deprivation; DL 1: The most socioeconomically favoured areas; DL5: The most socioeconomically deprived areas; D: Domicile; 95\% Cl: 95\% Confidence intervals; OR: Odds Ratio

\section{Acknowledgements}

Not applicable.

\section{Authors' contributions}

AN participated in the research design; AN, PP-Z and AO-A contributed to the acquisition and organization of databases; AN conducted the analysis; AN and PP-Z analysed the data; AN, MF-A and MJC-M wrote the original draft; AN, JMC, MJC-M, MF-A, JC-G, AO-A and PP-Z critically reviewed the content; JMC, PP-Z, and AN reviewed and edited the final manuscript; AN managed the funding acquisition; All authors have read and agreed to the published version of the manuscript. All authors read and approved the final manuscript.

\section{Authors' information}

Not applicable.

\section{Funding}

This research was partially funded by the research project "Cambios socioeconómicos y evolución de las desigualdades en mortalidad en áreas pequeñas de grandes ciudades en la Comunitat Valenciana" (PI16/00670), funded by the Instituto de Salud Carlos III (co-funded by the European Regional Development Fund).

Availability of data and materials

Data is available at the Valencian Community Mortality Registry.
Ethics approval and consent to participate

Not applicable.

\section{Consent for publication \\ Not applicable.}

\section{Competing interests}

The authors declare no conflict of interest.

\section{Author details}

${ }^{1}$ Research Unit for the Analysis of Mortality and Health Statistics, Department of Community Nursing, Preventive Medicine, Public Health and History of Science, University of Alicante, Alicante, Spain. ${ }^{2}$ Department of Health Psychology, University of Alicante, Alicante, Spain. ${ }^{3}$ Department of Nursing, University of Alicante, Alicante, Spain. ${ }^{4}$ Institute for Health and Biomedical Research of Alicante (ISABIAL- FISABIO Foundation), Alicante, Spain.

Received: 17 August 2020 Accepted: 11 November 2020

Published online: 03 December 2020

\section{References}

1. De Roo ML, Miccinesi G, Onwuteaka-Philipsen BD, Van Den Noortgate N, Van Den Block L, Bonacchi A, et al. Actual and preferred place of death of home-dwelling patients in four European countries: making sense of quality indicators. PLoS One. 2014;9(4):6-10. https://doi.org/10.1371/journal.pone. 0093762.

2. Gomes B, Higginson IJ. Factors influencing death at home in terminally ill patients with cancer: systematic review. Br Med J. 2006;332(7540):515-8. https://doi.org/10.1136/bmj.38740.614954.55.

3. Gomes B, Higginson IJ, Calanzani N, Cohen J, Deliens L, Daveson BA, et al. Preferences for place of death if faced with advanced cancer: a population survey in England, Flanders, Germany, Italy, the Netherlands, Portugal and Spain. Ann Oncol. 2012;23(8):2006-15. https://doi.org/10.1093/annonc/ mdr602.

4. Gomes B, Calanzani N, Gysels M, Hall S, Higginson IJ. Heterogeneity and changes in preferences for dying at home: A systematic review. BMC Palliative Care. 2013;12(7). https://doi.org/10.1186/1472-684X-12-7.

5. Gomes B, Calanzani N, Koffman J, Higginson IJ. Is dying in hospital better than home in incurable cancer and what factors influence this? A population-based study. BMC Med. 2015;13(1):1-14.

6. Pivodic L, Pardon K, Morin L, Addington-Hall J, Miccinesi G, CardenasTuranzas $M$, et al. Place of death in the population dying from diseases indicative of palliative care need: a cross-national population-level study in 14 countries. J Epidemiol Community Health. 2016;70(1):17-24. https://doi. org/10.1186/s12916-015-0466-5.

7. Cohen J, Bilsen J, Hooft P, Deboosere P, Wal G v d, Deliens L. Dying at home or in an institution. Using death certificates to explore the factors associated with place of death. Health Policy (New York). 2006;78(2-3):31929. https://doi.org/10.1016/j.healthpol.2005.11.003.

8. Cohen J, Pivodic L, Miccinesi G, Onwuteaka-Philipsen BD, Naylor WA, Wilson DM, et al. International study of the place of death of people with cancer: A population-level comparison of 14 countries across 4 continents using death certificate data. Br J Cancer. 2015;113(9):1397-404. https://doi.org/10. 1038/bjc.2015.312.

9. Dasch B, Blum K, Gude P, Bausewein C. Place of death: trends over the course of a decade. A population-based study of death certificates from the years 2001 and 2011. Dtsch Arztebl Int. 2015;112(29-30):496-504. https:// doi.org/10.3238/arztebl.2015.0496.

10. Gomes B, Pinheiro MJ, Lopes S, de Brito M, Sarmento VP, Lopes Ferreira P, et al. Risk factors for hospital death in conditions needing palliative care: Nationwide population-based death certificate study. Palliat Med. 2018;32(4): 891-901. https://doi.org/10.1177/0269216317743961.

11. Davies JM, Sleeman KE, Leniz J, Wilson R, Higginson IJ, Verne J, et al. Socioeconomic position and use of healthcare in the last year of life: a systematic review and meta-analysis. PLoS Med. 2019;16(4):1-23. https://doi. org/10.1371/journal.pmed.1002782.

12. Sleeman KE, Ho YK, Verne J, Glickman M, Silber E, Gao W, et al. Place of death, and its relation with underlying cause of death, in Parkinson's disease, motor neurone disease, and multiple sclerosis: a population-based study. Palliat Med. 2013;27(9):840-6. https://doi.org/10.1177/ 0269216313490436. 
13. Cabañero-Martínez MJ, Nolasco A, Melchor I, Fernández-Alcántara M, Cabrero-García J. Place of death and associated factors: a population-based study using death certificate data. Eur J Pub Health. 2019;29(4):608-15. https://doi.org/10.1093/eurpub/cky267.

14. Cabañero-Martínez MJ, Nolasco A, Melchor I, Fernández-Alcántara M, Cabrero-García J. Lugar de fallecimiento de las personas con enfermedades susceptibles de cuidados paliativos en las diferentes comunidades autónomas de España. An Sist Sanit Navar. 2020;43:69-80. https://doi.org/10. 23938/ASSN.0856.

15. Varani S, Dall'olio FG, Messana R, Tanneberger S, Pannuti R, Pannuti F, et al Clinical and demographic factors associated to the place of death in advanced cancer patients assisted at home in Italy. Prog Palliat Care. 2015; 23(2):61-7. https://doi.org/10.1179/1743291X14Y.0000000094.

16. Sasao S, Tanabe K, Morita T, Takahashi T, Yasuda H, Kashii T, et al. Facilityrelated factors influencing the place of death and home care rates for endstage cancer patients. J Palliat Med. 2015;18(8):691-6. https://doi.org/10. 1089/jpm.2014.0384.

17. Jeurkar N, Farrington S, Craig TR, Slattery J, Harrold JK, Oldanie B, et al. Which hospice patients with cancer are able to die in the setting of their choice? Results of a retrospective cohort study. J Clin Oncol. 2012;30(22): 2783-7. https://doi.org/10.1200/JCO.2011.41.5711.

18. Cohen J, Houttekier D, Onwuteaka-Philipsen B, Miccinesi G, Addington-Hal J, Kaasa S, et al. Which patients with cancer die at home? A study of six European countries using death certificate data. J Clin Oncol. 2010;28(13): 2267-73. https://doi.org/10.1200/JCO.2009.23.2850.

19. Neergaard MA, Brunoe AH, Skorstengaard MH, Nielsen MK. What socioeconomic factors determine place of death for people with life-limiting illness? A systematic review and appraisal of methodological rigour. Palliat Med. 2019;33(8):900-25. https://doi.org/10.1177/0269216319847089.

20. Proyecto MEDEA. Available online: http://www.proyectomedea.org (accessed on 26 July 2020)

21. Marí-Dell'Olmo M, Gotsens M, Palència L, Burström B, Corman D, Costa G, et al. Socioeconomic inequalities in cause-specific mortality in 15 European cities. J Epidemiol Community Health. 2015;69(5):432-41. https://doi.org/10. 1136/jech-2014-204312.

22. Borrell C, Marí-Dell'Olmo M, Serral G, Martínez-Beneito M, Gotsens M. Inequalities in mortality in small areas of eleven Spanish cities (the multicenter MEDEA project). Health Place. 2010;16(4):703-11. https://doi.org/ 10.1016/j.healthplace.2010.03.002.

23. Domínguez-Berjón MF, Borrell C, Cano-Serral G, Esnaola S, Nolasco A, Pasarín Ml, et al. Construcción de un índice de privación a partir de datos censales en grandes ciudades españolas (Proyecto MEDEA). Gac Sanit. 2008; 22(3):179-87. https://doi.org/10.1157/13123961.

24. Alonso-Babarro A, Astray-Mochales J, Domínguez-Berjón F, Gènova-Maleras R, Bruera E, Díaz-Mayordomo A, et al. The association between in-patient death, utilization of hospital resources and availability of palliative home care for cancer patients. Palliat Med. 2013;27(1):68-75. https://doi.org/10. 1177/0269216312442973.

25. Domínquez-Berión MF, Esteban-Vasallo MD, Zoni AC, Gènova-Maleras R, Astray-Mochales J. Place of death and associated factors among patients with amyotrophic lateral sclerosis in Madrid (Spain). Amyotroph Lateral Scler Front Degener. 2016;17(1-2):62-8. https://doi.org/10.3109/21678421.2015.1089908.

26. López-Campos JL, Ruiz-Ramos M, Mendez C, García-León J. Characteristics of subjects who died of chronic obstructive pulmonary disease in Andalusia in 2010 and 2011. J Palliat Med. 2013;16(12):1610-3. https://doi.org/10.1089/ jpm.2013.0310.

27. Murtagh FEM, Bausewein C, Verne J, Iris Groeneveld E, Kaloki YE, Higginson IJ. How many people need palliative care? A study developing and comparing methods for population-based estimates. Palliat Med. 2014;28(1): 49-58. https://doi.org/10.1177/0269216313489367.

28. Oliva-Arocas A, Pereyra-Zamora P, Copete JM, Vergara-Hernández C, Martínez-Beneito MA, Nolasco A. Socioeconomic inequalities in mortality among foreign-born and Spanish-born in small areas in cities of the mediterranean coast in Spain, 2009-2015. Int J Environ Res Public Health. 2020;17(13):1-18. https://doi.org/10.3390/ijerph17134672.

29. Nelson W. Statistical methods for the ratio of two multinomial proportions. Am Stat. 1972;26(3):22-7. https://doi.org/10.2307/2682861.

30. Centro de Investigaciones Sociológicas (CIS). Atención a pacientes con enfermedades en fase terminal. Madrid; 2009. Available online: http://www. cis.es/cis/export/sites/default/-Archivos/Marginales/2800_2819/2803/es2803. pdf (accessed on 23 October 2020).
31. Macfarlane M, Carduff E. Does place of death vary by deprivation for patients known to specialist palliative care services? BMJ Support Palliat Care. 2018;8(4):428-30. https://doi.org/10.1136/bmjspcare-2016-001099.

32. Ziwary SR, Samad D, Johnson CD, Edwards RT. Impact of place of residence on place of death in Wales: an observational study. BMC Palliat Care. 2017; 16(1):1-6. https://doi.org/10.1186/s12904-017-0261-5.

33. Davies AN, Waghorn M. Response to "does place of death vary by deprivation for patients known to specialist palliative care services?" by Macfarlane and Carduff. BMJ Support Palliat Care. 2019;9:358. https://doi. org/10.1136/bmjspcare-2019-001792.

34. Waghorn $M$, Young $H$, Davies $A$. Opinions of patients with cancer on the relative importance of place of death in the context of a "good death.". BMJ Support Palliat Care. 2011;1(3):310-4. https://doi.org/10.1136/bmjspcare2011-000041.

35. Garlo K, O'Leary JR, Van Ness PH, Fried TR. Caregiver burden in caregivers of older adults with advanced illness. J Am Geriatr Soc. 2010;12(58):2315-22. https://doi.org/10.1111/j.1532-5415.2010.03177.x.

36. Santos Salas A, Watanabe SM, Tarumi Y, Wildeman T, Hermosa García AM, Adewale B, et al. Social disparities and symptom burden in populations with advanced cancer: specialist palliative care providers' perspectives. Support Care Cancer. 2019;27(12):4733-44. https://doi.org/10.1007/s00520-019-04726-z.

37. Kahriman F, Zaybak A. Caregiver burden and perceived social support among caregivers of patients with cancer. Asian Pac J Cancer Prev. 2015; 16(8):3313-7. https://doi.org/10.7314/APJCP.2015.16.8.3313.

38. Wang Z, Ma C, Han H, He R, Zhou L, Liang R, et al. Caregiver burden in Alzheimer's disease: moderation effects of social support and mediation effects of positive aspects of caregiving. Int J Geriatr Psychiatry. 2018;33(9): 1198-206. https://doi.org/10.1002/gps.4910.

39. Amblàs-Novellas J, Murray SA, Espaulella J, Martori JC, Oller R, MartinezMuñoz M, et al. Identifying patients with advanced chronic conditions for a progressive palliative care approach: a cross-sectional study of prognostic indicators related to end-of-life trajectories. BMJ Open. 2016;6(9):e012340. https://doi.org/10.1136/bmjopen-2016-012340.

40. See D, Le B, Gorelik A, Eastman P. Symptom burden in malignant and nonmalignant disease on admission to a palliative care unit. BMJ Support Palliat Care. 2019:1-6. https://doi.org/10.1136/bmjspcare-2018-001560.

41. Comondore VR, Devereaux PJ, Zhou Q, Stone SB, Busse JW, Ravindran NC, et al. Quality of care in for-profit and not-for-profit nursing homes: systematic review and meta-analysis. BMJ. 2009;339(7717):381-4. https://doi. org/10.1136/bmj.b2732.

42. Yuan Y, Louis C, Cabral H, Schneider JC, Ryan CM, Kazis LE. Socioeconomic and geographic disparities in accessing nursing homes with high star ratings. J Am Med Dir Assoc. 2018;19(10):852-9. https://doi.org/10.1016/j. jamda.2018.05.017.

43. Garrote JM. The primary health care situation in Spain. World Med J. 2018; 64(1):12-8.

44. Cervero-Liceras F, McKee M, Legido-Quigley $H$. The effects of the financial crisis and austerity measures on the Spanish health care system: a qualitative analysis of health professionals' perceptions in the region of Valencia. Health Policy (New York). 2015;119(1):100-6. https://doi.org/10. 1016/j.healthpol.2014.11.003.

45. Gené-Badia J, Gallo P, Hernández-Quevedo C, García-Armesto S. Spanish health care cuts: penny wise and pound foolish? Health Policy (New York). 2012;106(1):23-8. https://doi.org/10.1016/j.healthpol.2012.02.001.

\section{Publisher's Note}

Springer Nature remains neutral with regard to jurisdictional claims in published maps and institutional affiliations. 